Marquette University

e-Publications@Marquette

$4-2009$

\title{
Thermal stability and flammability characteristics of ethylene vinyl acetate (EVA) composites blended with a phenyl phosphonate-intercalated layered double hydroxide (LDH), melamine polyphosphate and/or boric acid
}

Calistor Nyambo

Marquette University

Everson Kandare

University of Bolton

Charles A. Wilkie

Marquette University, charles.wilkie@marquette.edu

Follow this and additional works at: https://epublications.marquette.edu/chem_fac

Part of the Chemistry Commons

\section{Recommended Citation}

Nyambo, Calistor; Kandare, Everson; and Wilkie, Charles A., "Thermal stability and flammability characteristics of ethylene vinyl acetate (EVA) composites blended with a phenyl phosphonateintercalated layered double hydroxide (LDH), melamine polyphosphate and/or boric acid" (2009).

Chemistry Faculty Research and Publications. 87.

https://epublications.marquette.edu/chem_fac/87 
Marquette University

e-Publications@Marquette

\section{Chemistry Faculty Research and Publications/College of Arts and Sciences}

This paper is NOT THE PUBLISHED VERSION; but the author's final, peer-reviewed manuscript. The published version may be accessed by following the link in th citation below.

Polymer Degradation and Stability, Vol. 94, No. 4 (April 2009): 513-520. DOI. This article is @ Elsevier and permission has been granted for this version to appear in e-Publications@Marquette. Elsevier does not grant permission for this article to be further copied/distributed or hosted elsewhere without the express permission from Elsevier.

\section{Thermal Stability and Flammability Characteristics of Ethylene Vinyl Acetate (EVA) Composites Blended with A Phenyl Phosphonate-Intercalated Layered Double Hydroxide (LDH), Melamine Polyphosphate And/Or Boric Acid}

Calistor Nyambo

Department of Chemistry and Fire Retardant Research Facility, Marquette University, Milwaukee, WI Everson Kandare Centre for Materials Research and Innovation, University of Bolton, BL3 5AB, UK Charles A. Wilkie Department of Chemistry and Fire Retardant Research Facility, Marquette University, Milwaukee, WI

\section{Abstract}

A phenyl phosphonate-intercalated MgAl-LDH (MgAl-PPh), melamine polyphosphate (MP), and boric acid (BA) were independently and concomitantly added to neat ethylene vinyl acetate (EVA) copolymer at loading fractions of $10 \%(\mathrm{w} / \mathrm{w})$. The structural morphology of MgAl-PPh was established via powder X-ray diffraction 
(PXRD) and scanning electron microscopy (SEM) while the presence of phenyl phosphonate in the galleries was confirmed by Fourier transform infrared (FTIR). Thermogravimetric analysis (TGA) and cone calorimetry were used to evaluate the thermal stability and flammability behavior of EVA and its composites. While time-toignition is greatly reduced for EVA composites compared to the virgin polymer, there are remarkable reductions in the peak heat release rate (PHRR) which relates to a reduction in flame intensity. Synergistic effects were observed in cone calorimetry for the formulation containing MgAl-PPh, MP, and BA.

\section{Keywords}

EVA, Layered double hydroxide, Melamine polyphosphate, Boric acid, Synergy

\section{Introduction}

Ethylene vinyl acetate (EVA) copolymer is readily available in the form of rubber, thermoplastic elastomers, and plastic and is widely used in the wire and cable industry due to its desirable physico-chemical properties and its easy acceptance of additives [1]. The ease of ignition and subsequent flaming combustion with the release of large volumes of toxic smoke prohibit the application of EVA-based materials in high temperature service environments. A plausible solution to this problem is the addition of flame retardant additives which may improve the fire safety of EVA-based materials. Non-halogenated flame retardant additives, such as intumescent systems [2], [3], carbon nanotubes [4], [5], modified natural cationic clays [6], metal hydroxides [7], and oxides of group III and V elements [8]have been widely utilized with EVA. However, more recently synthetic clays, known as layered double hydroxides (LDH), have been used with EVA and do show flame retardancy potential [9], [10], [11], [12].

Layered double hydroxides are lamellar structured hydrotalcite-like compounds with anionic exchange properties similar to the extensively studied cationic clays such as montimorillonite. Their generic formula is $\left[\mathrm{M}_{1-x}{ }^{2+} \mathrm{M}_{x}{ }^{3+}(\mathrm{OH})_{2}\right]^{x+} \mathrm{A}_{x / m^{n-}} \cdot n \mathrm{H}_{2} \mathrm{O}$, where $\mathrm{M}^{2+}$ and $\mathrm{M}^{3+}$ are divalent and trivalent metal cations, such as $\mathrm{Mg}^{2+}$ and $\mathrm{Al}^{3+}$, respectively, and $\mathrm{A}^{n-}$ is interlayer anion, which is exchangeable such as $\mathrm{NO}_{3}{ }^{-}, \mathrm{CO}_{3}{ }^{2-}$, and $\mathrm{PO}_{4}{ }^{3-}$. The ability to exchange the interlayer anions introduces a fascinating design opportunity via which known potential flame retardant anions can be incorporated into the lamellar structure before adding the LDH to a polymer matrix. While magnesium hydroxide, aluminum hydroxide, and phosphorus-containing compounds have been extensively studied independently as flame retardant additives, their flame retardation efficiency in EVA may be improved by designing a phosphonate-intercalated MgAl-LDH which may prevent premature decomposition of phosphorus-containing additives. The anticipated water vapor from dehydroxylation of intralayer structures and the release of phosphorus derivatives during decomposition may decrease the amount of combustible volatiles while promoting char formation and subsequently inhibiting heat and mass transfer.

In the present study, we have explored the effect of a phosphonate-intercalated MgAl-LDH (MgAl-PPh) on the thermal and flammability behavior of EVA using thermogravimetric analysis (TGA) and cone calorimetry. Flame retardant/EVA blends containing MgAl-PPh and of $10 \%$ were also studied and compared to EVA composites containing MgAl-PPh.

\section{Experimental}

\subsection{Materials}

Magnesium nitrate hexahydrate, $\mathrm{Mg}\left(\mathrm{NO}_{3}\right)_{2} \cdot 6 \mathrm{H}_{2} \mathrm{O}$, aluminum nitrate nonahydrate, $\mathrm{Al}\left(\mathrm{NO}_{3}\right)_{3} \cdot 9 \mathrm{H}_{2} \mathrm{O}$, sodium hydroxide flakes, $\mathrm{NaOH}$ and glycerol (Aldrich Chemical Co.), phenyl phosphonic acid [PPh], $\left(\mathrm{C}_{6} \mathrm{H}_{5} \mathrm{PO}(\mathrm{OH})_{2}\right)(\mathrm{TCl})$, ethylene vinyl acetate copolymer, [EVA], (Escorene Ultra EVA UL $00218 C C 3$ from Exxon Mobil Chemical), boric acid [BA] Rio Tinto Inc., melamine polyphosphate (melapur 200/70 , [MP] (Ciba Specialty Chemicals)) were used as-received without further purification. Hydrotalcite, (pural MG63HT), referred herein as MgAl-carbonate LDH, was kindly provided by Sasol Germany, GmbH. 


\subsection{Preparation of MgAl-phenyl phosphate layered double hydroxide (MgAl-PPh LDH)}

The phenyl phosphonate intercalated MgAl-LDH (referred hereafter as MgAl-PPh) was prepared by rehydration of the calcined hydrotalcite (MgAl-carbonate) following a procedure reported by Dimotakis and Pinnavaia [13]. In a typical experiment, the MgAl-carbonate LDH was calcined in air at $450 \pm 10^{\circ} \mathrm{C}$ for $18 \mathrm{~h} .1 .0 \mathrm{~g}$ of the calcined material was then added to phenyl phosphonate solution $(0.1 \mathrm{M} ; 100 \mathrm{~mL})$ prepared by dissolving phenyl phosphonic acid in a $0.2 \mathrm{M}$ solution of $\mathrm{NaOH}$ in water/glycerol $(1: 2 \mathrm{v} / \mathrm{v})$ under a steady flow of nitrogen to exclude carbon dioxide at $50{ }^{\circ} \mathrm{C}$. It is imperative that $\mathrm{CO}_{2}$ is excluded since its presence will lead to the formation of a carbonate. The resulting slurry was aged at $50^{\circ} \mathrm{C}$ for $24 \mathrm{~h}$, filtered and washed several times with hot deionized/degassed water followed by drying at $100{ }^{\circ} \mathrm{C}$ in a vacuum oven.

\subsection{Preparation of EVA/LDH/melamine polyphosphate/boric acid composites}

Ethylene vinyl acetate composites were prepared via melt blending using established literature methods [14]. Melt blending was performed in a Brabender mixer at a temperature of $130^{\circ} \mathrm{C}$ at a screw speed of $60 \mathrm{rpm}$ for $8 \mathrm{~min}$. EVA composite samples were prepared by adding predetermined additive weight fractions of the hydrotalcite, MP, and/or BA to a measured portion of the copolymer in order to achieve a cumulative additive fraction of $10 \%(w / w)$. The constitutive proportions of EVA formulations are shown in Table 1 . A reference sample of unmodified EVA was obtained by following the same procedure only without any additive.

Table 1. Composition of EVA composites.

\begin{tabular}{|l|l|l|l|l|}
\hline Sample & EVA (\%) & MgAl-PPh (\%) & MP (\%) & BA (\%) \\
\hline EVA & 100 & 0 & 0 & 0 \\
\hline EVA/BA-10 & 90 & 0 & 0 & 10 \\
\hline EVA/MP-10 & 90 & 0 & 10 & 0 \\
\hline EVA/MgAl-PPh-10 & 90 & 10 & 0 & 0 \\
\hline EVA/MgAl-PPh/MP/BA-2/4/4 & 90 & 2 & 4 & 4 \\
\hline EVA/MgAl-PPh/MP/BA-4/2/4 & 90 & 4 & 2 & 4 \\
\hline EVA/MgAl-PPh/MP/BA-4/4/2 & 90 & 4 & 4 & 2 \\
\hline
\end{tabular}

\subsection{Instrumentation}

Powder X-ray diffraction measurements (PXRD) of the LDHs, char and their calcination products were recorded on a Rigaku, Miniflex II Desktop, X-ray diffractometer with Cu ( $\left.K_{\text {á }}\right)$ source $\lambda=1.54078 \AA$, from a sealed X-ray tube. The powdered samples were prepared and mounted on a glass holder while thin plaques of composites were fabricated via compression molding and mounted on aluminum sample holder. The data were collected at $2 \vartheta$ values of $0-60^{\circ}$ at a scan rate of $0.0833 \%$ s with a sampling width of 0.02 . Basal spacing of LDHs was obtained from averaging $00 /$ reflections $(I=3,6,9)$.

The scanning electron microcopy (SEM) image of the layered double hydroxide (MgAl-BP) was obtained via a Cambridge Stereoscan 200 with the sample coated with a conductive layer of gold.

Fourier transform infrared spectra of layered double hydroxides and their respective calcined products were obtained using the $\mathrm{KBr}$ disk method on a Nicolet Magna-IR 560 spectrometer operating at $1 \mathrm{~cm}^{-1}$ resolution in the $400-4000 \mathrm{~cm}^{-1}$ region.

Thermogravimetric analysis, (TGA) and differential thermal analysis (DTA) were performed on an SDT 2960 simultaneous DTA-TGA instrument from 50 to $800^{\circ} \mathrm{C}$ at a heating rate of $20^{\circ} \mathrm{C} / \mathrm{min}$ in $\mathrm{N}_{2}$, flowing at $85 \pm 5 \mathrm{~mL} / \mathrm{min}$, with sample sizes of $15.0 \pm 1.0 \mathrm{mg}$ contained in aluminum sample cups. All samples were run in triplicate and average values are reported; temperatures are considered accurate to $\pm 3{ }^{\circ} \mathrm{C}$ and the error on the fraction of non-volatile materials is $\pm 2 \%$. Calcination of the hydrotalcite, MgAl-carbonate was performed in a Thermolyne 1300 furnace at $450{ }^{\circ} \mathrm{C}$ for $18 \mathrm{~h}$. 
Approximately $30 \mathrm{~g}$ of EVA composite specimens were compression molded into $100 \mathrm{~mm} \times 100 \mathrm{~mm}$ square plaques of uniform thickness $(\sim 3 \mathrm{~mm}$ ) before cone calorimetry was performed on an Atlas Cone 2 instrument according to ASTM E 1354 at an incident flux of $35 \mathrm{~kW} / \mathrm{m}^{2}$ with a cone shaped heater; the spark was continuous until the sample ignited. All samples were run in triplicate and the average value, with standard deviation, is reported; results from cone calorimeter are generally considered to be reproducible to $\pm 10 \%$.

\section{Results and discussion}

\subsection{Structural characterization of the LDHs and their EVA composites}

\subsubsection{Infrared and X-ray diffraction analysis}

Fig. 1 shows the powder X-ray diffraction (PXRD) patterns of the precursor layered double hydroxide, MgAlcarbonate, its calcined product, and the phenyl phosphonate intercalated hydrotalcite, MgAl-PPh. PXRD patterns of MgAl-carbonate reveal narrow and equidistantly spaced $00 \mathrm{I}(I=3,6,9)$ basal reflections in the low angle region leaving no doubt that these materials are layered and possess a high degree of ordering in the $c$ dimension. Analysis of the positions of $00 /$ peaks using the Bragg equation gives an average $d$ spacing of 7.4 A. The PXRD pattern of the calcined hydrotalcite shows no basal reflections over the whole scanned range indicative of the possible presence of an amorphous mixture of $\mathrm{Mg}$ and Al oxides [15]. Upon re-hydration of the calcined phase with an aqueous solution containing phenyl phosphonate the layered structure was recovered. The resultant product, MgAl-PPh, exhibits strong and sharp $00 /$ basal reflections indicative of well-crystallized layered phases and its basal spacing is calculated to be $13.8 \AA$ which is twice that of MgAl-carbonate. The layered structure of MgAl-PPh is confirmed by the scanning electron microscopy images. The SEM image, Fig. 2 , shows that MgAl-PPh is composed mainly of plate-like particles with sharp edges stacked upon each other. No change in $d$ spacing was observed when MgAl-PPh LDH was combined with the EVA as shown by the XRD traces presented in Fig. 3. This observation indicates that a microcomposite has been formed.

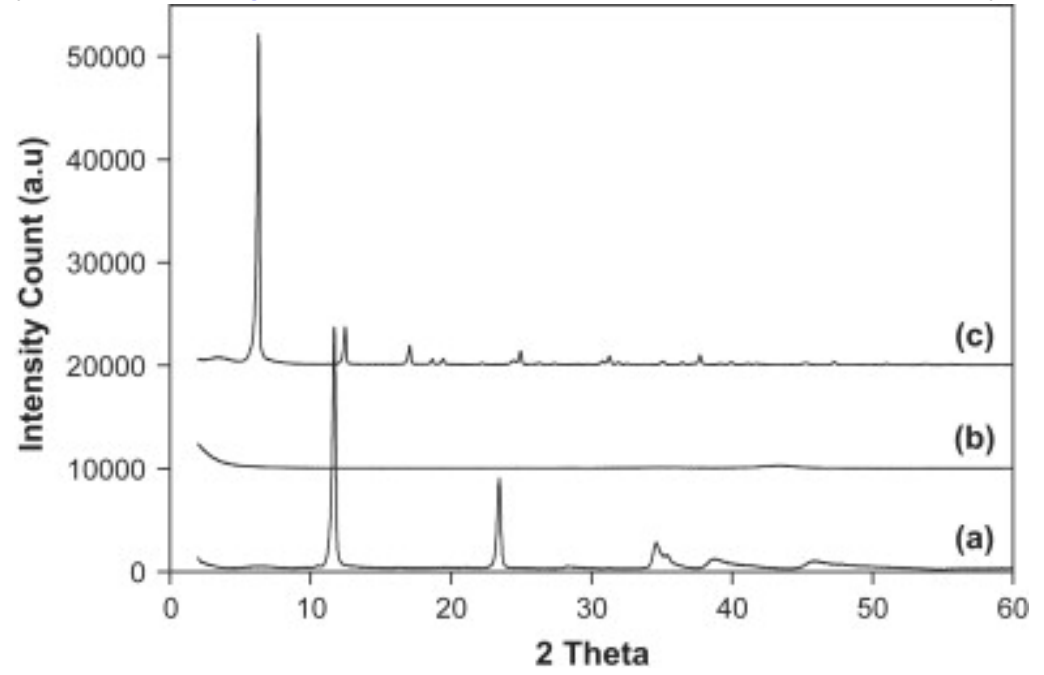

Fig. 1. Powder XRD pattern of (a) MgAl-carbonate, (b) MgAl-carbonate calcined at $450{ }^{\circ} \mathrm{C}$ for $18 \mathrm{~h}$, and (c) MgAl-PPh layered double hydroxide. Data are offset for clarity but not otherwise scaled. 


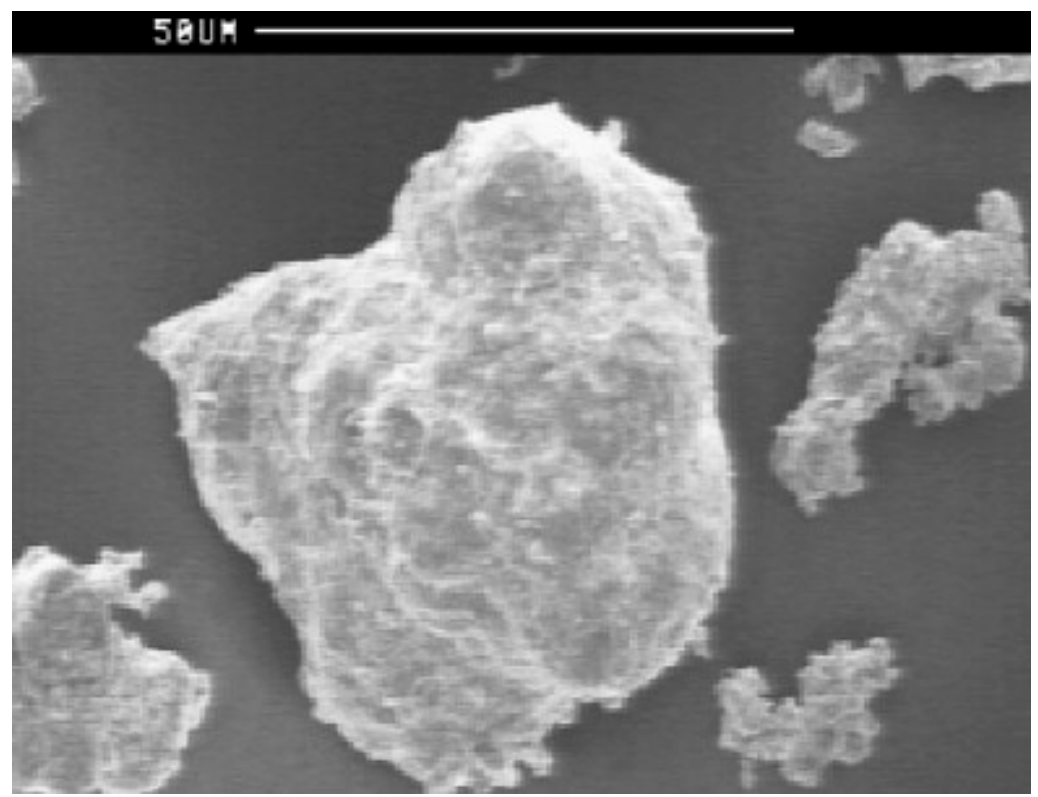

Fig. 2. The SEM image of MgAl-PPh layered double hydroxide.

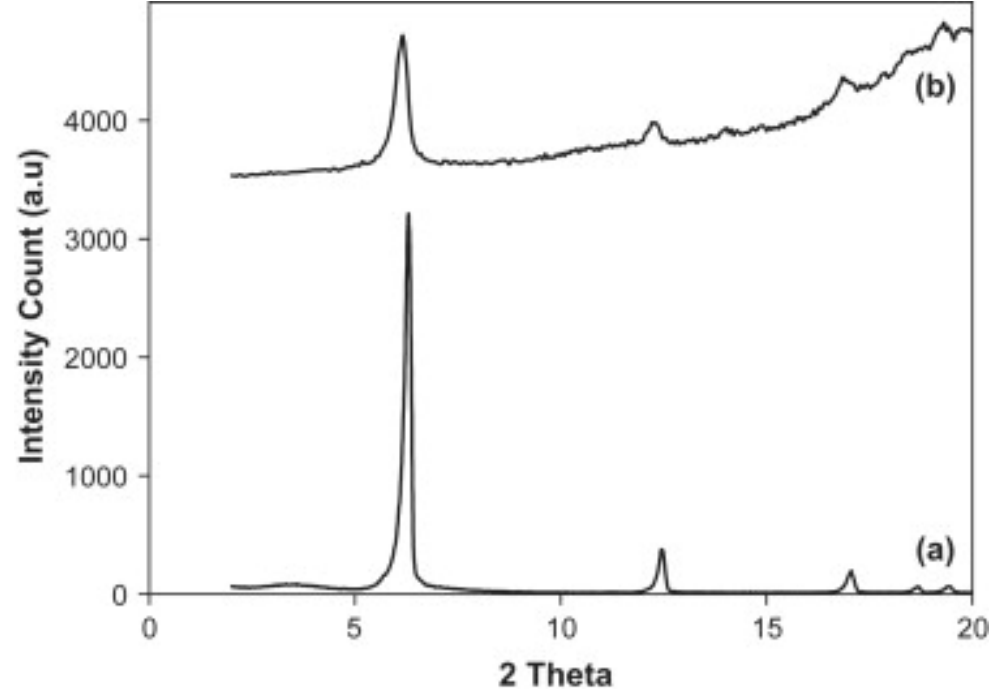

Fig. 3. The XRD patterns of (a) MgAl-PPh layered double hydroxide and (b) EVA/MgAl-PPh-10 composite. The FT-IR spectra of MgAl-carbonate and MgAl-PPh shown in Fig. 4 reveal the characteristic absorption bands of hydrotalcite-like compounds. Both MgAl-carbonate and MgAl-PPh show the absorption bands from $\mathrm{O}-\mathrm{H}$ stretching at about $3500 \mathrm{~cm}^{-1}, \delta(\mathrm{H}-\mathrm{OH})$ vibrations at about $1640 \mathrm{~cm}^{-1}$, and the lattice vibration of the M-O and $\mathrm{O}-\mathrm{M}-\mathrm{O}(\mathrm{M}=\mathrm{Mg}$ and $\mathrm{Al})$ groups in the low frequency region below $800 \mathrm{~cm}^{-1}$ [9]. The absorption bands at 1370 and $1060 \mathrm{~cm}^{-1}$ in the spectrum of $\mathrm{MgAl}-$ carbonate are assigned to the carbonate stretching. For the phosphonate intercalated LDH, MgAl-PPh, characteristic absorption peaks of phenyl phosphonate are evident; (i) $1443 \mathrm{~cm}^{-1}$ : sharp P-C stretching vibration, (ii) 1150, 1110, and $1018 \mathrm{~cm}^{-1}$ : vibrations of the $\mathrm{O}_{3} \mathrm{P}-\mathrm{C}$ group, and (iii) 762,733 , and $702 \mathrm{~cm}^{-1}$ (medium intensity): characteristic bands of the mono-substituted phenyl ring [16]. An absorption band at $1406 \mathrm{~cm}^{-1}$ also present in the FT-IR spectrum of the calcined MgAl-carbonate LDH may be due to free carbonates due residual carbonate after calcination or from atmospheric contamination which is hard to prevent. 


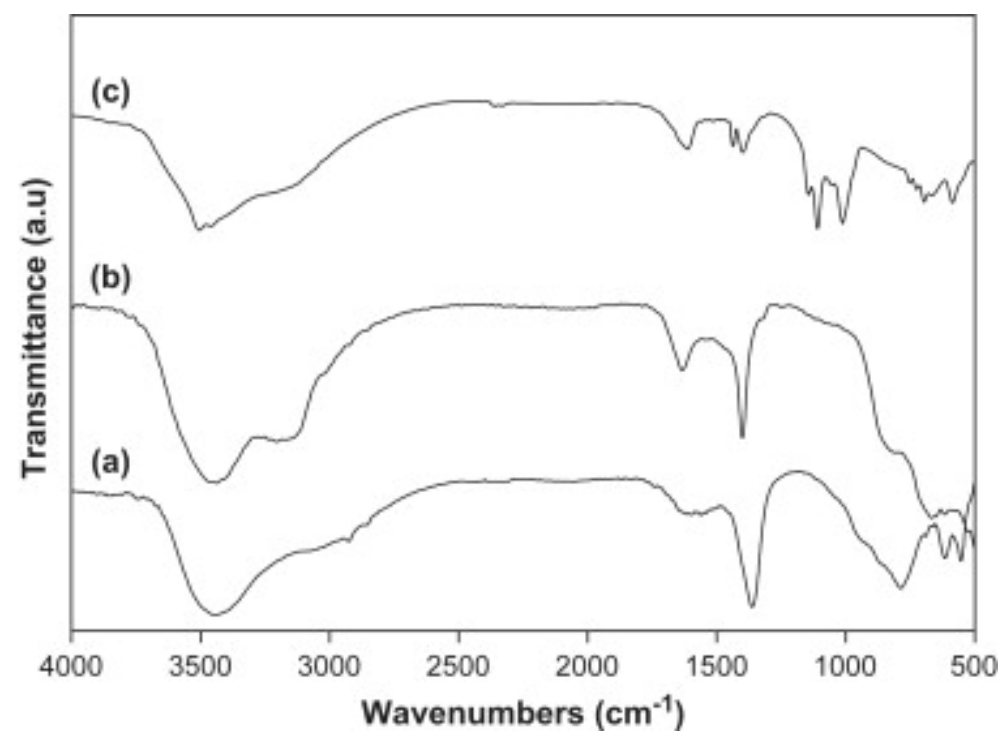

Fig. 4. FTIR spectra of (a) MgAl-carbonate, (b) MgAl-carbonate calcined at $450{ }^{\circ} \mathrm{C}$ for $18 \mathrm{~h}$, and (c) MgAl-PPh layered double hydroxide. Spectra are offset for clarity.

\subsection{Thermal stability of potential flame retardants and their EVA composites}

\subsubsection{Thermal degradation behavior of potential flame retardant additives}

Fig. 5 shows the TGA mass loss profiles of the potential flame retardant additives MgAl-PPh, melamine polyphosphate, and boric acid in an inert atmosphere. The thermal degradation of MgAl-PPh displays a fourstep process in the temperature range of $50-800{ }^{\circ} \mathrm{C}$. The first two steps, occurring between 60 and $250{ }^{\circ} \mathrm{C}$, may be due to the loss of water of hydration and intercalated water molecules equivalent to $13 \%$ of the LDH. The third step occurs between 300 and $500{ }^{\circ} \mathrm{C}$ and is probably due to dehydroxylation of the $-\mathrm{MgAl}-\mathrm{OH}-$ intralayer structure while the fourth and most prominent step between 500 and $600{ }^{\circ} \mathrm{C}$ may be attributed to deanation as reported in previous work [17], [18], [19]. The production of water vapor, the presence of phosphate, and formation of metal oxides during the thermal degradation of the layered double hydroxide may serve to improve the thermal stability of EVA/MgAl-PPh blends via: (i) cooling of the specimen environment by water vapor, (ii) formation of charred layers that may be promoted by the chemical interactions between polymeric fragments and phosphate derivatives [20], and (iii) catalytic chemical activities that may slow the scission of polymer chains while promoting fragment recombinations.

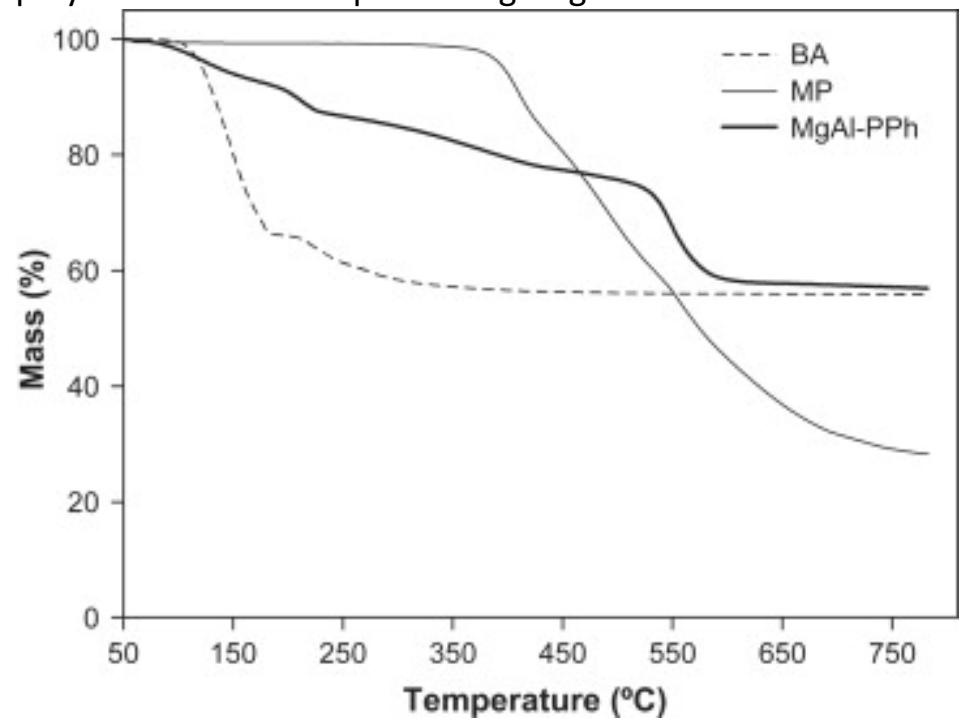

Fig. 5. TGA curves for boric acid (dashed line), melamine polyphosphate (solid line) and MgAl-PPh (bold line) at $20^{\circ} \mathrm{C} /$ min under a $\mathrm{N}_{2}$ atmosphere. 
From the TGA curve in Fig. 5 , it can be seen that melamine polyphosphate does not show any significant weight loss at temperatures below $400^{\circ} \mathrm{C}$. However, above this temperature, melamine polyphosphate undergoes an endothermic decomposition process releasing melamine which subsequently sublimes or degrades, releasing ammonium and water [21]. The phosphate is converted into phosphoric acid and polyphosphoric acids which may promote the formation of residual char in the condensed phase [22]; the char yield of MP at $800{ }^{\circ} \mathrm{C}$ is $28 \%$. The thermal degradation of boric acid, Fig. 5, follows a two-step mechanism: the first step between 100 and $180{ }^{\circ} \mathrm{C}$, corresponding to a weight loss of $34 \%$, is due to the dehydration of boric acid into metaboric acid, $\mathrm{HBO}_{2}$ while the second step with a mass loss of $10 \%$ between 180 and $400{ }^{\circ} \mathrm{C}$, may be attributed to the dehydration of $\mathrm{HBO}_{2}$ into boron oxide, $\mathrm{B}_{2} \mathrm{O}_{3}$, leaving $56 \%$ residual char. Such high levels of residual char in the form of "hard glass", $\mathrm{B}_{2} \mathrm{O}_{3}$, are imperative in the formation of the ultimate physical barrier with a high structural integrity [23].

\subsubsection{Thermogravimetric behavior of EVA and its composites}

The TGA curves for unmodified EVA and its MP, BA, and, MgAl-PPh composites are shown in Fig. 6while the data are presented in Table 2. The mass loss profile of EVA shows a two stage degradation pathway with the first step attributed to the elimination of acetate side groups (deacetylation) leaving behind an unsaturated polymer backbone or polyene [24], [25], [26], while the second step is due to the allylic chain scission of the polyene to reach full thermal degradation at high temperatures [27]. The onset of thermal degradation for unmodified EVA, measured as the temperature at which $10 \%$ mass loss occurs, $T_{10}$, is $351{ }^{\circ} \mathrm{C}$ while $T_{\max }$, the temperature at which maximum mass loss occurs, is $456^{\circ} \mathrm{C}$. The addition of BA, MP, and MgAl-PPh at a loading fraction of $10 \%$ by weight leads to the shift in degradation processes to higher temperatures.

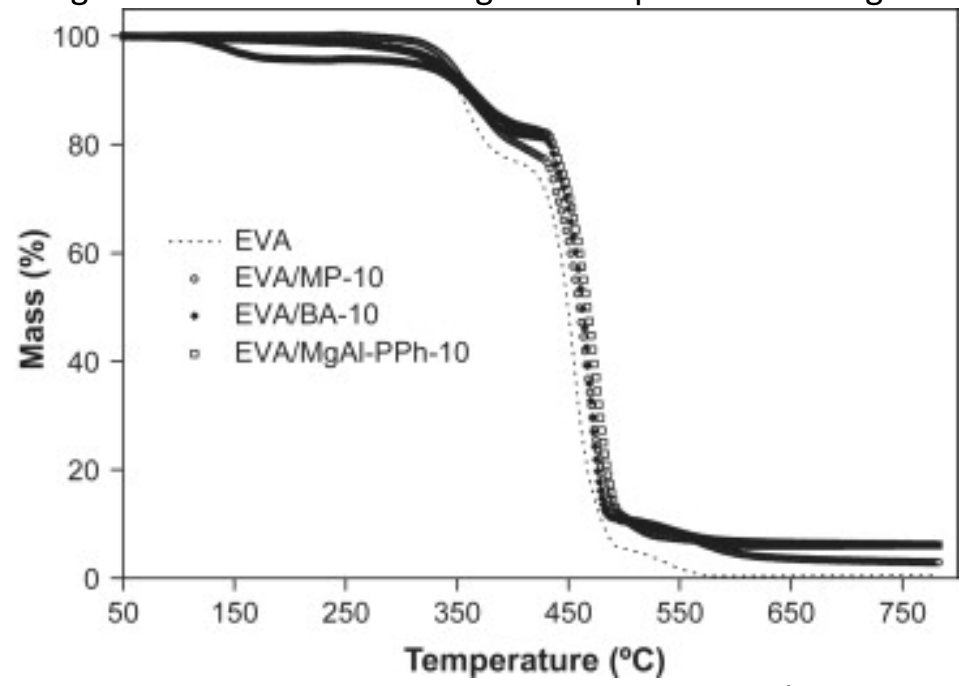

Fig. 6. TGA curves for neat EVA (dotted line), EVA/MP-10 (filled circles), EVA/BA-10 (filled diamonds), and EVA/MgAl-PPh-10 (empty squares) at $20^{\circ} \mathrm{C} / \mathrm{min}$ under a $\mathrm{N}_{2}$ atmosphere.

Table 2. TGA data for flame-retarded EVA formulations.

\begin{tabular}{|c|c|c|c|c|c|c|c|c|}
\hline Sample & $T_{10}\left({ }^{\circ} \mathrm{C}\right)$ & $\Delta T_{10}\left({ }^{\circ} \mathrm{C}\right)$ & $\begin{array}{l}\text { OSE } \\
(\%)\end{array}$ & $\begin{array}{l}\text { Char at } \\
800^{\circ} \mathrm{C} \\
(\%)\end{array}$ & $\begin{array}{l}\text { TGA 1st } \\
\text { stage }\end{array}$ & & $\begin{array}{l}\text { TGA } \\
\text { 2nd } \\
\text { stage }\end{array}$ & \\
\hline & & & & & $\begin{array}{l}\text { Temp. } \\
\text { range } \\
\left({ }^{\circ} \mathrm{C}\right)\end{array}$ & $\begin{array}{l}\text { Peak pos.; } \\
\text { (peak } \\
\operatorname{max.})^{\mathrm{a}}\left({ }^{\circ} \mathrm{C}\right) ;(\% \\
\left.{ }^{\circ} \mathrm{C}^{-1}\right)\end{array}$ & $\begin{array}{l}\text { Temp. } \\
\text { range } \\
\left({ }^{\circ} \mathrm{C}\right)\end{array}$ & $\begin{array}{l}\text { Peak pos.; } \\
\text { (peak } \\
\operatorname{max.})^{\mathrm{a}}\left({ }^{\circ} \mathrm{C}\right) ;(\% \\
\left.{ }^{\circ} \mathrm{C}^{-1}\right)\end{array}$ \\
\hline EVA & 351 & - & - & 1 & $\begin{array}{l}240- \\
400\end{array}$ & $358 ;(0.5)$ & $\begin{array}{l}400- \\
500\end{array}$ & $456 ;(2.1)$ \\
\hline EVA/BA-10 & 355 & 4 & 1503 & 6 & $\begin{array}{l}240- \\
415\end{array}$ & $363 ;(0.3)$ & $\begin{array}{l}415- \\
500\end{array}$ & $468 ;(2.5)$ \\
\hline
\end{tabular}




\begin{tabular}{|c|c|c|c|c|c|c|c|c|}
\hline EVA/MP-10 & 360 & 9 & 1402 & 3 & $\begin{array}{l}240- \\
415\end{array}$ & $360 ;(0.3)$ & $\begin{array}{l}415- \\
500\end{array}$ & $468 ;(1.7)$ \\
\hline $\begin{array}{l}\text { EVA/MgAl- } \\
\text { PPh-10 }\end{array}$ & 361 & 10 & 1939 & 6 & $\begin{array}{l}240- \\
410\end{array}$ & $366 ;(0.2)$ & $\begin{array}{l}410- \\
500\end{array}$ & $476 ;(1.8)$ \\
\hline $\begin{array}{l}\text { EVA/MgAl- } \\
\text { PPh/MP/BA- } \\
2 / 4 / 4\end{array}$ & 364 & 13 & 1337 & 5 & $\begin{array}{l}240- \\
415\end{array}$ & $363 ;(0.3)$ & $\begin{array}{l}415- \\
500\end{array}$ & $470 ;(2.2)$ \\
\hline $\begin{array}{l}\text { EVA/MgAl- } \\
\text { PPh/MP/BA- } \\
4 / 2 / 4\end{array}$ & 364 & 13 & 1835 & 6 & $\begin{array}{l}240- \\
415\end{array}$ & $369 ;(0.3)$ & $\begin{array}{l}415- \\
500\end{array}$ & $471 ;(2.0)$ \\
\hline $\begin{array}{l}\text { EVA/MgAl- } \\
\text { PPh/MP/BA- } \\
4 / 4 / 2\end{array}$ & 364 & 13 & 1614 & 5 & $\begin{array}{l}240- \\
415\end{array}$ & $365 ;(0.3)$ & $\begin{array}{l}415- \\
500\end{array}$ & $469 ;(2.4)$ \\
\hline
\end{tabular}

${ }^{a}$ Peak max. is the derivatized thermal degradation (DTG) response/signal value at the peak position while Peak pos. is the peak location with respect to temperature.

The addition of MP to EVA at $10 \%$ weight fraction leads to a slight delay in the thermal degradation processes of EVA as shown in Fig. 6 . The onset of thermal degradation, $T_{10}$, is increased by $9{ }^{\circ} \mathrm{C}$; the temperature at which the maximum mass loss rate recorded is increased from 456 to $468{ }^{\circ} \mathrm{C}$ and the residual char yield slightly increased by $2.3 \%$. At temperatures above $400{ }^{\circ} \mathrm{C}$, melamine polyphosphate undergoes endothermic decomposition releasing melamine, which subsequently sublimes or decomposes into incombustible $\mathrm{NH}_{3}$; this process acts as a heat sink cooling the specimen. The release of phosphate derivatives may lead to the formation of phosphoric acids which are known to promote char formation, therefore shielding the condensed combustible polymer. The interaction between the envisaged degradation products of MP such as melamine, $\mathrm{NH}_{3}$, phosphoric acids, and those of EVA induces the shift in degradation temperatures observed. However, the observed shift in degradation temperatures and the residual char at $800^{\circ} \mathrm{C}$ are no more than the calculated values, suggesting that while MP antagonistically delays the degradation process in the lower temperature regime eventually all the polymer matrix degrades at higher temperatures.

The thermal degradation profile of EVA/BA composite, shown in Fig. 6, suggests that the addition of boric acid leads to the destabilization of EVA in the lower temperature regime $\left(100-350^{\circ} \mathrm{C}\right)$. Boric acid degrades to form $\mathrm{B}_{2} \mathrm{O}_{3}$ releasing water as discussed above. The calculated mass loss from boric acid of $4.4 \%$ at temperatures below $350{ }^{\circ} \mathrm{C}$ attributed to the loss of water vapor agrees very well with the observed mass loss of $4.3 \%$ observed in Fig. $6 . \mathrm{H}_{3} \mathrm{BO}_{3}$ loses water below $350^{\circ} \mathrm{C}$ and the resultant probable product, $\mathrm{B}_{2} \mathrm{O}_{3}$, is expected to improve the thermal stability of EVA at higher temperatures. The onset of thermal degradation, $T_{10}$, is slightly increased by $4{ }^{\circ} \mathrm{C}$; the temperature at which the maximum mass loss rate is recorded is increased from 456 to $468{ }^{\circ} \mathrm{C}$ and the residual char yield increased by $5.5 \%$.

The addition of a phosphonate intercalated hydrotalcite-like LDH, MgAl-PPh, influences the thermal degradation of EVA more than MP or BA, Fig. 6. EVA/MgAl-PPh-10 follows the degradation pattern similar to that of EVA but the degradation temperatures are elevated. The onset of thermal degradation is enhanced by $10^{\circ} \mathrm{C}$ while the temperature at which decomposition occurs at the maximum rate is increased by $20^{\circ} \mathrm{C}$ relative to EVA. The shift in degradation temperatures may be attributed to the evolution of water, the presence of phosphate derivatives, and the probable catalytic effect due to the formation of mixed metal oxides during the thermal degradation of MgAl-PPh. MgAl-PPh may act via its decomposition to promote char formation thus protecting the underlying polymer hence decreasing the rate of degradation of EVA.

Mass difference curves, $\triangle$ mass\% (mass\% of EVA composites minus mass\% of unmodified EVA at the same temperature) for EVA/BA-10, EVA/MP-10, and EVA/MgAl-PPh-10 composites are shown in Fig. 7. Positive $\Delta$ mass\% profiles are indicative of enhancement in thermal stability of EVA following addition of the additives 
while negative $\Delta$ mass\% imply an adverse effect of the additives on the thermal stability of the polymer matrix. Boric acid greatly compromises the thermal stability of EVA at temperatures below $350^{\circ} \mathrm{C}$; but, it promotes char formation at higher temperatures, perhaps due to the presence of the heat resistant $\mathrm{B}_{2} \mathrm{O}_{3}$. A slight destabilization effect is observed below $350^{\circ} \mathrm{C}$ for EVA/MgAl-PPh-10 while the addition of MP has no adverse effect on the thermal stability of EVA over the entire temperature range. While MP does not lower the thermal stability of EVA at low temperatures, it also does not effectively promote char formation as boric acid and MgAlPPh do.

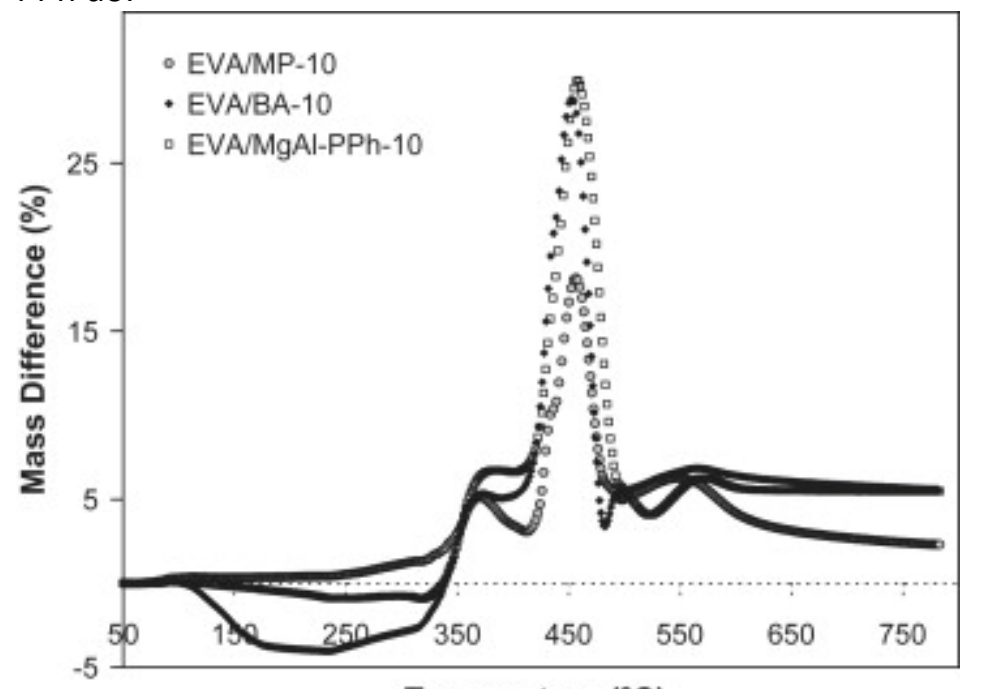

Temperature $\left({ }^{\circ} \mathrm{C}\right)$

Fig. 7. Curves of mass loss differences as a function of degradation temperature for EVA composites at $10 \%$ loadings; EVA/MP-10 (filled circles), EVA/BA-10 (filled diamonds), and EVA/MgAl-PPh-10 (empty squares).

A quantitative assessment of the overall thermal stabilization effect (OSE) of BA, MP, and MgAl-PPh was evaluated using an established method in literature [17]. The OSE values are positive for all three composites suggesting that at $10 \%$ additive fraction all the additives do enhance the overall thermal stability of EVA over the temperature region studied. The calculated OSE values for EVA/BA-10, EVA/MP-10, and EVA/MgAl-PPh-10 are 1503,1402 , and $1939 \%$ respectively. These values suggest that MgAl-PPh is more effective at improving the thermal stability of EVA than boric acid or melamine polyphosphate. The release of water vapor, phosphate derivatives, and the presence of mixed oxides during the thermal degradation of EVA/MgAl-PPh-10 may serve to enhance the thermal stability of EVA via different pathways including; (i) the presence of endothermic heat sinks, (ii) promotion of char formation due to the presence of phosphorus derivatives in the condensed phase, (iii) chemical interactions of polymer fragments with or over mixed metal oxides.

Fig. 8 shows the thermal degradation of EVA composites containing all three additives used simultaneously at a cumulative additive fraction of 10\% (EVA/MgAl-PPh/MP/BA-2/4/4, EVA/MgAl-PPh/MP/BA-4/2/4, and EVA/MgAl-PPh/MP/BA-4/4/2) while the data are presented in Table 2. The TGA profiles of these composites are similar and are shifted to higher degradation temperatures relative to EVA. The onset of degradation for these three composites occurs at a temperature of $364{ }^{\circ} \mathrm{C}$ which is an increase of $13{ }^{\circ} \mathrm{C}$ relative to EVA. The maximum mass loss rate occurs at approximately $470{ }^{\circ} \mathrm{C}$ for all three samples, a significant increase from $456{ }^{\circ} \mathrm{C}$ recorded for the control sample, EVA. 


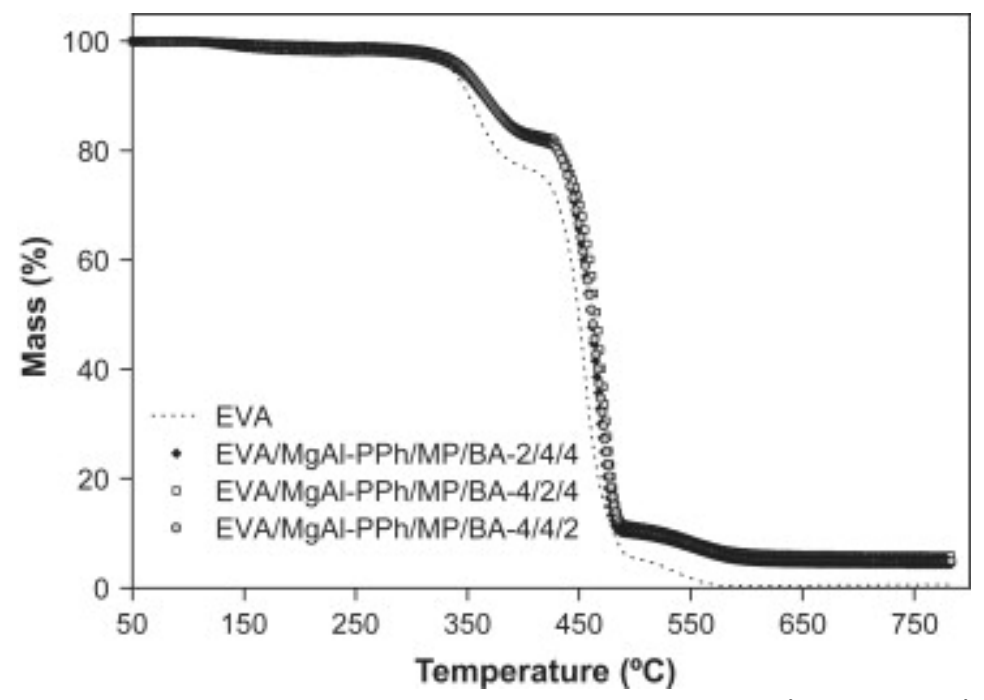

Fig. 8. TGA curves for neat EVA (dotted line), EVA/MgAl-PPh/MP/BA-2/4/4 (filled diamonds), EVA/MgAl$\mathrm{PPh} / \mathrm{MP} / \mathrm{BA}-4 / 2 / 4$ (empty squares), and EVA/MgAl-PPh/MP/BA-4/4/2 (filled circles) at $20^{\circ} \mathrm{C} / \mathrm{min}$ under a $\mathrm{N}_{2}$ atmosphere.

Mass difference curves of these three samples, Fig. 9, show a slight destabilization effect in the temperature region below $350^{\circ} \mathrm{C}$. While the patterns for mass difference curves are similar, EVA/MgAl-PPh/MP/BA-4/2/4 is the most thermally stabilized in the temperature region where the fastest rate of mass loss occurs. The calculated OSE values for EVA/MgAl-PPh/MP/BA-2/4/4, EVA/MgAl-PPh/MP/BA-4/2/4, and EVA/MgAl$\mathrm{PPh} / \mathrm{MP} / \mathrm{BA}-4 / 4 / 2$ are 1337,1835 , and $1614 \%$ respectively. These values suggest the following order of thermal stability in accordance with OSE values: EVA/MgAl-PPh/MP/BA-2/4/4 < EVA/MP-10 < EVA/BA-10 < EVA/MgAl$\mathrm{PPh} / \mathrm{MP} / \mathrm{BA}-4 / 4 / 2<\mathrm{EVA} / \mathrm{MgAl}-\mathrm{PPh} / \mathrm{MP} / \mathrm{BA}-4 / 2 / 4<\mathrm{EVA} / \mathrm{MgAl}-\mathrm{PPh}-10$. From these data, it may be concluded that MgAl-PPh has the most thermal stabilization effect while EVA/MgAl-PPh/MP/BA-2/4/4 is the least stabilized composite.

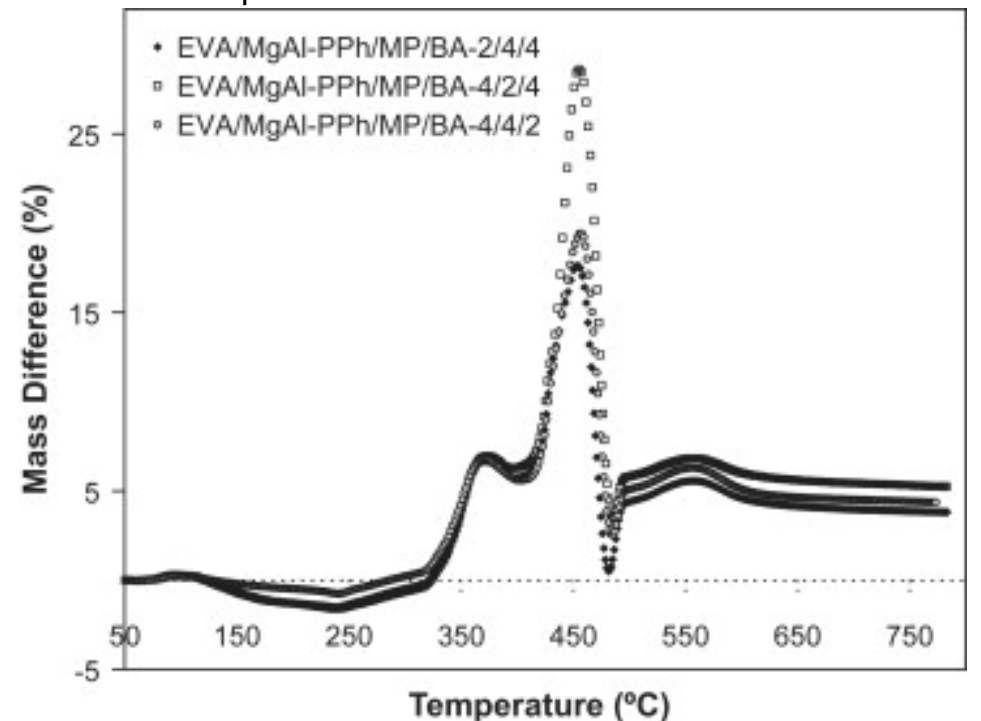

Fig. 9. Curves of mass loss differences as a function of degradation temperature for EVA composites at $10 \%$ loadings; EVA/MgAl-PPh/MP/BA-2/4/4 (filled diamonds), EVA/MgAl-PPh/MP/BA-4/2/4 (empty squares), and EVA/MgAl-PPh/MP/BA-4/4/2 (filled circles).

\subsection{Flammability characterization of EVA and its composites}

Cone calorimetry was used to evaluate the flammability behavior of EVA and its composites. Various parameters obtained or derived from experimental cone calorimetry results can be correlated to large-scale fire tests which are used to predict the burning behavior of materials in real fire scenarios. Fig. 10 shows the heat release rate 
(HRR) versus time curves for EVA, EVA/BA-10, EVA/MP-10, and EVA/MgAl-PPh-10 and the data are presented in Table 3 and the plots of total heat release (THR) as a function of time for EVA are shown in Fig. 11. The fire growth index (FIGRA) used as a flame spread indicator parameter is calculated as the ratio of PHRR to the timeto-PHRR. The lower the FIGRA value the higher the fire safety of a given material. The FIGRA value for EVA is calculated as $8.2 \mathrm{~kW} / \mathrm{m}^{2} \mathrm{~s}$.

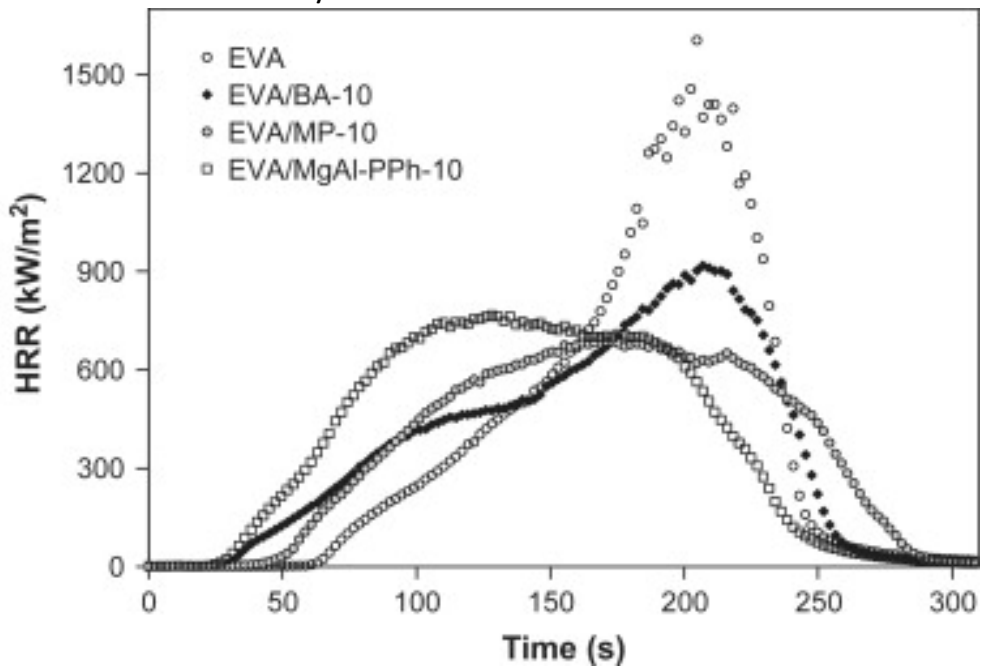

Fig. 10. Heat release rate curves neat EVA (empty circles), EVA/MP-10 (filled circles), EVA/BA-10 (filled diamonds), and EVA/MgAl-PPh-10 (empty squares) from cone calorimetry measurements at $35 \mathrm{~kW} / \mathrm{m}^{2}$.

Table 3. Cone calorimetry data for EVA and its composites at $35 \mathrm{~kW} / \mathrm{m}^{2}$.

\begin{tabular}{|c|c|c|c|c|c|c|c|}
\hline Sample & $T_{\text {ign }}(\mathrm{s})$ & $\begin{array}{l}\operatorname{PHRR}\left(\mathrm{kW} / \mathrm{m}^{2}\right) \\
(\% \text { red) }\end{array}$ & $t_{\mathrm{PHRR}}(\mathrm{s})$ & $\begin{array}{l}\text { THR } \\
\left(\mathrm{MJ} / \mathrm{m}^{2}\right)\end{array}$ & $\begin{array}{l}\text { AMLR } \\
\left(\mathrm{g} / \mathrm{sm}^{2}\right)\end{array}$ & $\begin{array}{l}\mathrm{FPI} \\
\left(\mathrm{kW} / \mathrm{m}^{2} \mathrm{~s}\right)\end{array}$ & $\begin{array}{l}\text { FIGRA } \\
\left(\mathrm{kW} / \mathrm{m}^{2} \mathrm{~s}\right)\end{array}$ \\
\hline EVA & $65 \pm 2$ & $1680 \pm 29$ & $204 \pm 8$ & $124 \pm 2$ & $20 \pm 2$ & 26 & 8.2 \\
\hline EVA/BA-10 & $35 \pm 5$ & $899 \pm 66(46)$ & $207 \pm 8$ & $112 \pm 2$ & $16 \pm 3$ & 26 & 4.3 \\
\hline EVA/MP-10 & $47 \pm 11$ & $715 \pm 47(57)$ & $206 \pm 28$ & $112 \pm 1$ & $14 \pm 4$ & 15 & 3.4 \\
\hline $\begin{array}{l}\text { EVA/MgAl-PPh- } \\
10\end{array}$ & $33 \pm 3$ & $793 \pm 40(53)$ & $140 \pm 38$ & $117 \pm 1$ & $17 \pm 2$ & 24 & 5.7 \\
\hline $\begin{array}{l}\text { EVA/MgAl- } \\
\mathrm{PPh} / \mathrm{MP} / \mathrm{BA}-2 / 4 / 4\end{array}$ & $29 \pm 1$ & $669 \pm 34(60)$ & $141 \pm 10$ & $114 \pm 1$ & $14 \pm 1$ & 23 & 4.7 \\
\hline $\begin{array}{l}\text { EVA/MgAl- } \\
\text { PPh/MP/BA-4/2/4 }\end{array}$ & $31 \pm 4$ & $680 \pm 33(60)$ & $140 \pm 8$ & $115 \pm 2$ & $15 \pm 1$ & 22 & 4.9 \\
\hline $\begin{array}{l}\text { EVA/MgAl- } \\
\mathrm{PPh} / \mathrm{MP} / \mathrm{BA}-4 / 4 / 2\end{array}$ & $30 \pm 2$ & $671 \pm 8(60)$ & $118 \pm 6$ & $114 \pm 1$ & $14 \pm 1$ & 22 & 5.7 \\
\hline
\end{tabular}

$T_{\text {ign, }}$ time-to-ignition; PHRR, peak heat release rate; (\% red.), reduction in PHRR; $t_{\text {PHRR, }}$, time to peak heat release rate; THR, total heat release; AMLR, average mass loss rate; FPI, fire performance index; FIGRA, fire growth rate. 


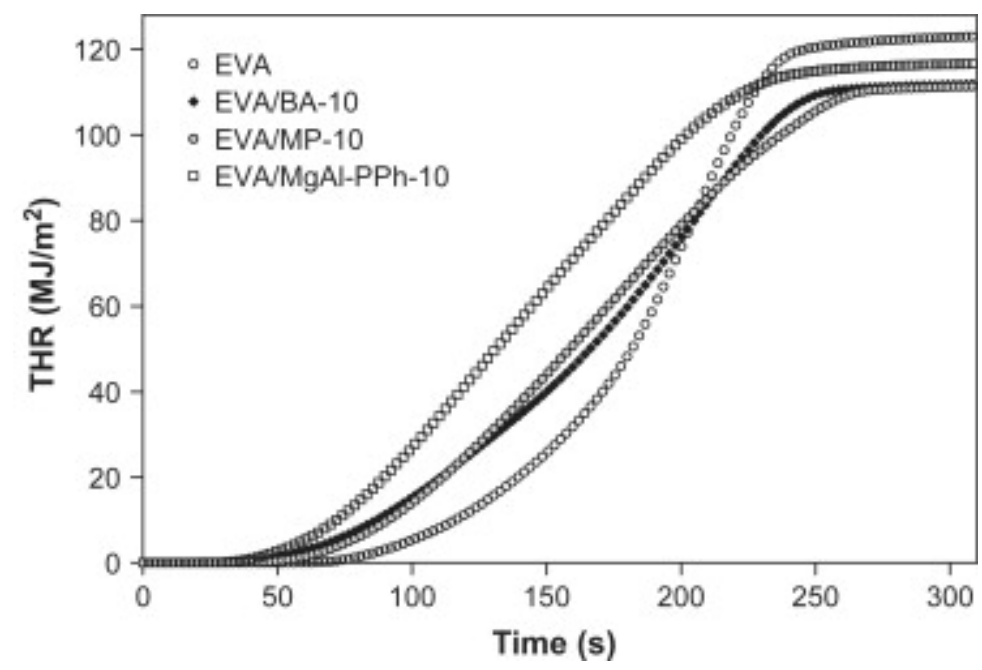

Fig. 11. The total heat release (THR) rate curves neat EVA (empty circles), EVA/MP-10 (filled circles), EVA/BA-10 (filled diamonds), and EVA/MgAl-PPh-10 (empty squares) from cone calorimetry measurements at $35 \mathrm{~kW} / \mathrm{m}^{2}$.

For EVA/BA-10 the HRR versus time curve is characterized by a shoulder from the time of sustained ignition, which is $35 \mathrm{~s}$, up until after $150 \mathrm{~s}$ when a sharp peak centered at $207 \mathrm{~s}$ is observed. The PHRR value of EVA is reduced by about $46 \%$ from a value of 1680 to $899 \mathrm{~kW} / \mathrm{m}^{2}$ following the addition of boric acid. The calculated FPI value for EVA/BA-10 $\left(26 \mathrm{~kW} / \mathrm{m}^{2} \mathrm{~s}\right)$ is the same as that calculated for EVA, while its FIGRA value is lower by a factor of two, Table 3 . Despite the reduction in PHRR, there is no improvement in overall fire safety for EVA/BA10 because the time-to-ignition is remarkably reduced upon addition of boric acid. However, once ignition occurs flame spread is slower for EVA/BA-10 when compared to EVA. A notable reduction in the THR value from 124 to $112 \mathrm{MJ} / \mathrm{m}^{2}$ is observed following addition of boric acid. The inevitable production of heat resistant $\mathrm{B}_{2} \mathrm{O}_{3}$ and the release of water vapor during the decomposition of boric acid in the presence of EVA may be responsible for the observed reduction in both the PHRR and the THR. A ceramic-like $\mathrm{B}_{2} \mathrm{O}_{3}$ layer would slow mass and heat transfer to the pyrolysis zone while the water vapor produced would serve to quench the flame, hence reducing its intensity. The reduction in PHRR and THR can be linked to the observed reduction in the AMLR calculated as $16 \mathrm{~g} / \mathrm{s} \mathrm{m}^{2}$.

The addition of MP significantly reduces the time-to-ignition from 65 to $47 \mathrm{~s}$ as well as the AMLR from 20 to $14 \mathrm{~g} / \mathrm{s} \mathrm{m}^{2}$. There is a remarkable reduction in the PHRR value from 1680 to $715 \mathrm{~kW} / \mathrm{m}^{2}$ a $57 \%$ reduction with no change in the time it takes for the flame intensity to peak. The fire performance index (FPI), a parameter defined as the ratio of PHRR to time-to-ignition, is independent of the specimen geometry and can be used to evaluate the fire resistance of a material. The lower the FPI value the more fire safe a material is. The FPI value obtained for EVA is $26 \mathrm{~kW} / \mathrm{m}^{2} \mathrm{~s}$ while that determined for EVA/MP-10 is $15 \mathrm{~kW} / \mathrm{m}^{2} \mathrm{~s}$ suggesting that MP has a high flame retardant efficiency. These results are corroborated by an observed $58 \%$ reduction in the FIGRA value of EVA/MP-10. The THR value reported for EVA/MP-10 $\left(112 \mathrm{MJ} / \mathrm{m}^{2}\right)$ is lower than observed for EVA $\left(124 \mathrm{MJ} / \mathrm{m}^{2}\right)$ and this suggests that the amount of heat evolved during decomposition of the later is lower. The presence of MP may lead to the formation of a physical char layer that retards the flaming process via the retardation of mass transfer of combustibles and oxygen as well as heat penetration into the pyrolysis zone. Decomposition products from $\mathrm{MP}$, such as melamine and $\mathrm{NH}_{3}$, may lead to the dilution of the combustion atmosphere while the presence of phosphorus in the condensed phase promotes char formation; both of these events improve the flame retardancy of EVA composites [9].

The HRR versus time curve for EVA/MgAl-PPh-10 has a single plateau-like feature peaking at $793 \mathrm{~kW} / \mathrm{m}^{2}$ after $140 \mathrm{~s}$. Addition of the phosphonate-intercalated hydrotalcite at $10 \%$ weight fraction leads to a $53 \%$ reduction in the PHRR and a slightly lower AMLR of $17 \mathrm{~g} / \mathrm{s} \mathrm{m}^{2}$. The envisaged presence of phosphorus in the condensed phase inescapably offers a high possibility of phosphorus derivatives reacting with EVA resin to form more stable char networks with $\mathrm{P}-\mathrm{O}-\mathrm{P}$ and $\mathrm{P}-\mathrm{O}-\mathrm{C}$ linkages, as reported in the literature [28], [29]. These charred structures, 
together with the release of water vapor and the possible catalytic role played by mixed $\mathrm{Mg}$ and Al oxides, are implicated in the reduction in PHRR and AMLR. There is no improvement in the fire resistance of EVA following addition of MgAl-PPh as indicated by a similar FPI value $\left(24 \mathrm{~kW} / \mathrm{m}^{2} \mathrm{~s}\right)$ to that of EVA, however, the fire growth rate is lower for the former. The reduction in THR is lower than that observed following the addition of boric acid or melamine polyphosphate to EVA suggesting that MgAl-PPh is not as effective in reducing the amount of combustible matter produced during the flaming combustion process.

The concomitant effect of boric acid, melamine polyphosphate and MgAl-PPh on the flammability behavior of EVA in the samples, EVA/MgAl-PPh/MP/BA-2/4/4, EVA/MgAl-PPh/MP/BA-4/2/4, and EVA/MgAl-PPh/MP/BA$4 / 4 / 2$ is also studied via cone calorimetry. Fig. 12 shows the heat release rate (HRR) versus time curves for $\mathrm{EVA} / \mathrm{MgAl}-\mathrm{PPh} / \mathrm{MP} / \mathrm{BA}-2 / 4 / 4$, EVA/MgAl-PPh/MP/BA-4/2/4, and EVA/MgAl-PPh/MP/BA-4/4/2 while the data are presented in Table 3. The HRR profiles for these samples are similar within experimental error, all having a plateau-like resemblance with the PHRR values between 669 and $680 \mathrm{~kW} / \mathrm{m}^{2}$ after about $140 \mathrm{~s}$. The observed PHRR values show an average 60\% reduction when compared to that for EVA while the AMLR is reduced to an average of $14 \mathrm{~g} / \mathrm{s} \mathrm{m}^{2}$. A reduction in THR from 124 to an average $114 \mathrm{MJ} / \mathrm{m}^{2}$ is observed. A slight improvement in fire resistance as indicated by a reduction in the FPI value from 126 to an average of $122 \mathrm{~kW} / \mathrm{m}^{2} \mathrm{~s}$ is observed. The fire growth rate is remarkably reduced by the simultaneous addition of these potential fire retardants, Table $\underline{3}$.

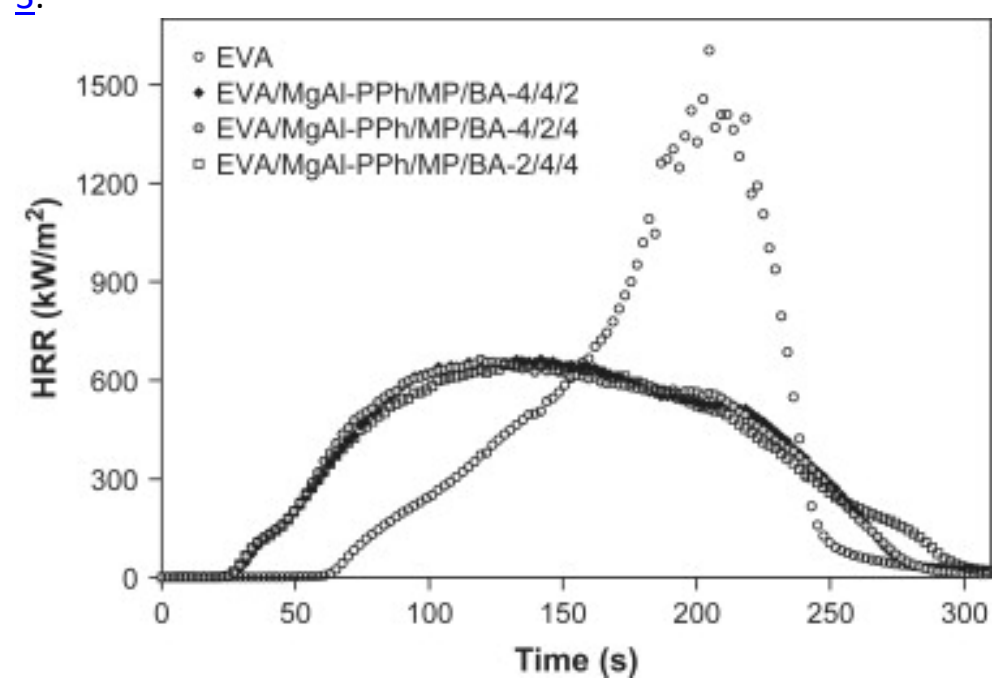

Fig. 12. Heat release rate curves for neat EVA (empty circles), EVA/MgAl-PPh/MP/BA-2/4/4 (empty squares), EVA/MgAl-PPh/MP/BA-4/2/4 (filled circles), and EVA/MgAl-PPh/MP/BA-4/4/2 (filled diamonds) from cone calorimetry measurements at $35 \mathrm{~kW} / \mathrm{m}^{2}$.

The percent reduction in the PHRR when the three additives are used simultaneously is about $60 \%$. In order to assess possible chemical interactions between these additives or their decomposition products in enhancing the flame retardancy of EVA, expected reductions in PHRR for EVA/MgAl-PPh/MP/BA-2/4/4, EVA/MgAl$\mathrm{PPh} / \mathrm{MP} / \mathrm{BA}-4 / 2 / 4$, and EVA/MgAl-PPh/MP/BA-4/4/2 were calculated assuming that each of the additives would act independently. The calculated percent reductions were found to be 51,52 , and $53 \%$ for EVA/MgAl$\mathrm{PPh} / \mathrm{MP} / \mathrm{BA}-2 / 4 / 4, \mathrm{EVA} / \mathrm{MgAl}-\mathrm{PPh} / \mathrm{MP} / \mathrm{BA}-4 / 2 / 4$, and EVA/MgAl-PPh/MP/BA-4/4/2 respectively. These values are lower than the experimentally observed values of $60 \%$ suggesting that the flame retardancy effect of the three additives when used together is more than mere additive, in fact this reflects synergism. The presence of $\mathrm{Mg}$ and $\mathrm{Al}$ metal oxides, together with phosphorus and boron may lead to the formation of highly flame retardant species, such as aluminum phosphate, boron phosphate, or boron-aluminum phosphate, which are very efficient physical and thermal barriers protecting the underlying polymers, according to the literature [29]. Other products from the decomposition of the additives, such as melamine, $\mathrm{NH}_{3}$, and water, may in their own respect have changed the decomposition mechanism of EVA. While the simultaneous addition of three potential 
flame retardants does not significantly reduce the total heat evolved or the average mass loss rate, the improvement in PHRR alone is equally important as it means a reduction in flame intensity.

\section{Conclusions}

EVA composites containing a layered phenyl phosphonate-intercalated inorganic/organic hybrid (MgAl-PPh), melamine polyphosphate, and boric acid were prepared via melt blending and their morphology evaluated using XRD and TEM. The inclusion of these potential flame retardant additives in EVA resulted in an improvement in the overall thermal stability and char formation. When MgAl-PPh was added at a $10 \%$ weight fraction the resultant EVA composite showed the greatest enhancement in thermal stability. The flammability behavior of flame retarded EVA composites was evaluated via cone calorimetry. Addition of MgAl-PPh, BA and MP at weight percent of $10 \%$ resulted in significant reductions in the time to sustained ignition and the peak heat release rate (PHRR) values. Similar reductions are observed for the average mass loss rate (AMLR) suggesting that the reductions in PHRR are due to the slower rate at which combustible volatiles are produced. However, the total heat evolved during combustion is not significantly affected by the presence of the additives. Synergistic interactions between the three flame retardants studied in this work may be responsible for more than additive flame retardancy effect observed with the reduction in PHRR when all these additives are used simultaneously.

\section{Acknowledgements}

Partial support of this work provided by the US Department of Commerce, National Institute of Standards and Technology, Fire Research Division under grant number 60NANBD6016 is gratefully acknowledged. The authors gratefully thank Dr Jeanne Hossenlopp and Dr Walid Awad for helpful discussions.

Recommended articlesCiting articles (102)

\section{References}

[1] S.K. Dutta, A.K. Bhownick, P.G. Mukunda, T.K. Chaki. Thermal degradation studies of electron beam cured ethylene-vinyl acetate copolymer. Polym Degrad Stab, 50 (1995), pp. 75-82

[2] F. Laoutid, L. Ferry, E. Leroy, J.M. Lopez Cuesta. Intumescent mineral fire retardant systems in ethylenevinyl acetate copolymer: effect of silica particles on char cohesion. Polym Degrad Stab, 91 (2006), pp. 2140-2145

[3] D.-Y. Wang, X.-X. Cai, M.-H. Qu, Y. Liu, J.-S. Wang, Y.-Z. Wang. Preparation and flammability of a novel intumescent flame-retardant poly(ethylene-co-vinyl acetate) system. Polym Degrad Stab, 93 (2008), pp. 2186-2192

[4] S. Peeterbroeck, M. Alexandre, J.B. Nagy, C. Pirlot, A. Fonseca, N. Moreau, et al. Polymer-layered silicatecarbon nanotube nanocomposites: unique nanofiller synergistic effect. Compos Sci Technol, 64 (2004), pp. 2317-2323

[5] F. Fengge Gao, G. Beyer, Q. Yuan. A mechanistic study of fire retardancy of carbon nanotube/ethylene vinyl acetate copolymers and their clay composites. Polym Degrad Stab, 89 (2005), pp. 559-564

[6] M. Alexandre, P. Dubois. Polymer-layered silicate nanocomposites: preparation, properties and uses of a new class of materials. Mater Sci Eng R Reports, 28 (2000), pp. 1-63

[7] Zhang J, Hereid J, Hagen M, Bakirtzis D, Delichatsios MA. Effects of nanoclay and fire retardants on fire retardancy of a polymer blend of EVA and LDPE. Fire Safety J, in press. doi:10.1016/j.firsaf.2008.10.005.

[8]C. Baillet, L. Delfosse. The combustion of polyolefins filled with metallic hydroxides and antimony trioxide. Polym Degrad Stab, 30 (1990), pp. 89-99

[9] L. Ye, B. Qu. Flammability characteristics and flame retardant mechanism of phosphate-intercalated hydrotalcite in halogen-free flame retardant EVA blends. Polym Degrad Stab, 93 (2008), pp. 918-924

[10] G. Zhang, P. Ding, M. Zhang, B. Qu. Synergistic effects of layered double hydroxide with hyperfine magnesium hydroxide in halogen-free flame retardant EVA/HFMH/LDH nanocomposites. Polym Degrad Stab, 92 (2007), pp. 1715-1720 
[11] L. Du, B. Qu, Z. Xu. Flammability characteristics and synergistic effect of hydrotalcite with microencapsulated red phosphorus in halogen-free flame retardant EVA composite. Polym Degrad Stab, 91 (2006), pp. 995-1001

[12] G. Camino, A. Maffezzoli, M. Braglia, M. De Lazzaro, M. Zammarano. Effect of hydroxides and hydroxycarbonate structure on fire retardant effectiveness and mechanical properties in ethylenevinyl acetate copolymer. Polym Degrad Stab, 74 (2001), pp. 457-464

[13] E.D. Dimotakis, T.J. Pinnavaia. New route to new layered double hydroxides intercalated by organic anions: precursors to polyoxometalate-pillared derivatives. Inorg Chem, 29 (1990), pp. 2393-2394

[14] D. Wang, J. Zhu, Q. Yao, C.A. Wilkie. A comparison of various methods for the preparation of polystyrene and poly(methyl methacrylate) clay nanocomposites. Chem Mater, 14 (2002), pp. 3837-3843

[15] F.R. Costa, A. Leuteritz, U. Wagenknecht, D. Jehnichen, L. Häußler, G. Heinrich. Intercalation of Mg-Al layered double hydroxide by anionic surfactants: preparation and characterization. Appl Clay Sci, 27 (2004), pp. 159-177

[16] H. Nijs, A. Clearfield, E.F. Vansant. The intercalation of phenyl phosphonic acid in layered double hydroxides.. Microporous Mesoporous Mater, 23 (1998), pp. 97-108

[17] C. Nyambo, E. Kandare, D. Wang, C.A. Wilkie. Flame-retarded polystyrene: investigating chemical interactions between ammonium polyphosphate and MgAl layered double hydroxide. Polym Degrad Stab, 93 (2008), pp. 1656-1663

[18] C. Nyambo, P. Songtipya, E. Manias, M. Jimenez-Gasco, C.A. Wilkie. Effect of MgAl-layered double hydroxide exchanged with linear alkyl carboxylates on fire retardancy of PMMA and PS. J Mater Chem, 28 (2008), pp. 4827-4838

[19] C. Nyambo, D. Wang, C.A. Wilkie. Will layered double hydroxides give nanocomposites with polar or nonpolar polymers? Polym Adv Technol (2008) doi:10.1002/pat.1272

[20]S. Bourbigot, S. Duquesne. Fire retardant polymers: recent developments and opportunities. J Mater Chem, 17 (2007), pp. 2283-2300

[21]L. Costa, G. Camino. Thermal behavior of melamine. J Therm Anal, 34 (1988), pp. 423-429

[22]S. Jahromi, W. Gabriëlse, A. Braam. Effect of melamine polyphosphate on thermal degradation of polyamides: a combined X-ray diffraction and solid-state NMR study. Polymer, 44 (2003), pp. 25-37

[23] M. Jimenez, S. Duquesne, S. Bourbigot. Intumescent fire protective coating: toward a better understanding of their mechanism of action. Thermochim Acta, 449 (2006), pp. 16-26

[24] M. Zanetti, G. Camino, R. Thomann, R. Mülhaupt. Synthesis and thermal behaviour of layered silicate-EVA nanocomposites. Polymer, 42 (2001), pp. 4501-4507

[25] A. Riva, G. Camino, L. Fomperie, P. Amigouët. Fire retardant mechanism in intumescent ethylene vinyl acetate compositions. Polym Degrad Stab, 82 (2003), pp. 341-346

[26] M. Zanetti, T. Kashiwagi, L. Falqui, G. Camino. Cone calorimeter combustion and gasification studies of polymer layered silicate nanocomposites. Chem Mater, 14 (2002), pp. 881-887

[27] M.C. Costache, D.D. Jiang, C.A. Wilkie. Thermal degradation of ethylene-vinyl acetate copolymer nanocomposites. Polymer, 46 (2005), pp. 6947-6958

[28] Q. Wu, J. Lu, B. Qu. Preparation and characterization of microcapsulated red phosphorous and its flameretardant mechanism in halogen-free flame retardant polyolefins. Polym Int, 52 (2003), pp. 1326-1331

[29] U. Braun, B. Schartel, M.A. Fichera, C. Jäger. Flame retardancy mechanisms of aluminum phosphinate in combination with melamine polyphosphate and zinc borate in glass-fibre reinforced polyamide 6,6. Polym Degrad Stab, 92 (2007), pp. 1528-1545 